\title{
Axial-Swept Influence on Inner Flow Performance of HP Steam Turbine Based on CFD
}

\author{
Zi-Ming Feng $\mathbb{D},{ }^{1}$ Chenhao Guo, ${ }^{1}$ Bingkun Wei, ${ }^{2}$ Wei Cui $\mathbb{D},{ }^{1}$ \\ Huibin $\mathrm{Gu}^{1}{ }^{1}$ and Jindong $\mathrm{Zhang}^{1}$ \\ ${ }^{1}$ School of Mechanical Science and Engineering, Northeast Petroleum University, Daqing, China \\ ${ }^{2}$ Daqing Oilfield Powerlift Pump Industry Co. Ltd., China \\ Correspondence should be addressed to Zi-Ming Feng; xueyuanfzm@163.com and Wei Cui; cuiweivv@126.com
}

Received 22 March 2019; Revised 29 June 2019; Accepted 3 July 2019; Published 25 July 2019

Academic Editor: Gareth A. Vio

Copyright (c) 2019 Zi-Ming Feng et al. This is an open access article distributed under the Creative Commons Attribution License, which permits unrestricted use, distribution, and reproduction in any medium, provided the original work is properly cited.

\begin{abstract}
Swept blade technology was used to redesign the supercritical steam turbine sets that could improve the inner-efficiency of turbine sets and decrease the consumption of coal the noxious gas such as NOx. The eighth high-pressure stages, including static and rotor cascades, were selected as tested prototypes that were blew in the low-velocity wind tunnel. We used the five-hole ball head needle to measure the aerodynamic parameters distribution along the width and span direction of the high-pressure stage cascades. With the inkblot display technology, the limit flow spectrums were displaced in the blade surface and the endwalls. These tested data could be used to check the simulation results of CFD software. To improve the efficiency of the steam turbine high-pressure (HP) stage, we selected the supercritical steam turbine HP stage cascade blade as the prototype to research into its inner flow performance of the axial-swept blade by the CFD software. Two different redesigned blades, with $\pm 20^{\circ}$, swept angle, and $30 \%$ swept height, named axial fore-swept and axial aft-swept, were built up. The stage passages flow field of the prototype blade, and the two redesigned swept blades were simulated using CFD software with stage interface planes between the stages. The CFD simulation results indicated that the leading edge of swept blades influenced the inlet flow field; the pressure in aft-swept blade stage in both endwalls was higher than in the middle and was beneficial to improve the passage flow properties of HP stage. But for the fore-swept HP stage, its pressure distribution was lower in both endwalls than in the middle and not beneficial to passage flow.
\end{abstract}

\section{Introduction}

In recent years, as oil and coal were becoming scarce and their prices were rising, people paid more attention to the problems of energy conservation and environmental protection than before; at the same time, many countries planned to develop steam turbine power station with high efficiency. Improving turbine machinery internal efficiency is one of the eternal targets for turbine mechanical engineers and scientific researchers. People had attempted many methods to improve the internal efficiency of the steam turbine and have achieved a lot of achievements. Later, it is found to be a good idea following the design concept of an aircraft wing. The swept concept of turbine cascade came from the swept aircraft wing.

From 1950 to 1970, Beatty [1], Godwin [2], Smith [3], Lewis [4], and so on researched low-speed tests of aft-swept blades with a straight leading edge. Gostelow \& Smith's [5] thought there is no evidence to indicate the aft-swept blade can raise the flow efficiency in the laboratory experiment. In 1997, Wadia [6] found that the fore-swept blade can increase the efficiency and the surge margin. Sasaki [7] defined swept angle and swept height in the two-dimensional coordinate system. Based on the difference between the inner and outer flows, Zou et al. [8] defined the swept angle in the threedimensional coordinate system.

Weingold et al. [9] measured the performance of a threestage compressor in the fore-swept and aft-swept blades and concluded that the velocity stall of corner zones disappeared and the overall efficiency increased by $1 \%$. Corsini \& Rispoli [10] also thought that the fore-swept can reduce the flow loss. In document [11], the influence of forward-swept blade on the gaps flow was studied. It is considered that the swept blade increased the stall margin and reduced the flow loss in the cascade passage. 
Although the swept blade of compressors had been widely researched and used, the studies of turbine were not enough.

Feng et al. $[12,13]$ considered that the flow loss of axial aftswept static blade cascades is less than the prototype blade cascades, and the axial aft-swept rotor is nearly the same as the prototype blade. Bhaskar [14] designed a fore-apart swept blade and a lean blade; the change part was near the tip regions of axial flow turbine rotor blades. Bhaskar's results show that the two redesign blades can reduce about 20 25\% tip loss against prototype blade at $0^{\circ}$ and $10^{\circ}$ incidences and the swept can reduce the wake loss a little.

Shi et al. [15] conducted on the unsteady simulation of the flow fields of the forward-swept rotor and concluded that the inlet circumferential total pressure distortion had caused the deterioration of performance. Liu et al. [16] used the full cavitation model to predict the cavitation performances of pumps under the designed point condition and near the stall point condition to investigate the effects of the swept blade on the cavitation performance and distribution of pressure on blade surfaces of an axial flow pump. According to the numerical results, the swept blade changes the hump characteristic of the axial flow pump, controls the onset and growth of the secondary flows, and recovers the low energy fluid in the endwalls. Bamberger et al. [17] researched the aerodynamics and noise of the swept fan by CFD and developed a high efficiency and low acoustic fan at the design point. Larwood et al. [18] developed a new sweep rotor that can increase efficiency and capture more wind energy without increasing blade load.

In 2015, Neshat et al. [19] investigated the simultaneous effects of the sweep and lean of the blades in one stage of a transonic compressor on its performance. The numerical results indicated that the backward sweep rotor blade increased the stage efficiency by $0.5 \%$ at design conditions, while the stall margin reduces, and the chocking mass flow rate diminished by $1.5 \%$. A series of swept and straight cascades was modeled and simulated by CFD package shown in the document [20]. The results indicate that blade sweep does affect inlet radial equilibrium, such as blade camber angles, solidity. Halder et al. [21] researched an unswept blade and a $10^{\circ}$ backward-swept blade, respectively. It was found that the backward-swept blade strongly affects the blade stall margin. It was also observed that the flow separation of the swept and unswept blades occurs near the trailing edge and the leading edge, respectively. Jeong et al. [22] conducted a computational study to investigate the rotor blade sweep effect on the aerodynamics of turbine stage with and without tip gap and found that the positive sweep blades show a better aerodynamic performance than the prototype blade. Ding et al. [23] introduced an optimal design method of swept blades of Horizontal Axis Wind Turbines, which comprehensively take both annual energy productions (AEP) and blade root loads into account.

In 2017, Khalafallah et al. [24] investigated the effect of blade curvature, sweep starting point, and sweep direction on the wind turbine performance and found that the best performance was obtained when the starting blade sweeps at $25 \%$ of blade radius of different directions of the sweep. Pavese et al. [25] researched the backward-swept blades for passive load alleviation on wind turbines. They concluded that mildly and purely backward-swept shapes are the best option because they allow the wind turbine to achieve load alleviations without a large increase of the blade root torsional extreme and life-time equivalent fatigue moment.

In 2018, Feng et al. [26] used CFD technology to simulate the aerodynamic performance of steam turbine nozzle cascade and found that the aft-swept blade can effectively improve the corresponding flow characteristics and reduce the total pressure loss. Meanwhile, it has better aerodynamic performance than the straight blade and the fore-swept blade. Kaya et al. [27] investigated the aerodynamic performance of Horizontal Axis Wind Turbines (HAWTs) with forward and backward-swept blades and found that the forward-swept blades can increase the performance while the backwardswept blades tend to decrease the thrust coefficient. To model and analyze the effect of the circumferential nonuniformity on the flow field of a swept cascade, a kind of stress transport model was integrated into the throughflow model by $3 \mathrm{D}$ numerical simulation. The results show that the nonuniformity induced by the inviscid blade force will reorganize the inlet flow field of the blade passage and change the inlet flow angle, thus causing the redistribution of the radial balance of the inlet [28]. In 2019, Achilles et al. [29] presented a concept of an actively controlled horizontal axis wind turbine through varying blade tip sweep. A modified Blade Element Momentum model was used in the simulations of wind turbine that the results meet very well with the preliminary results.

Swept blade technology has been used in the fan, compressor, turbine, wind turbine, and pump et al. by test research and CFD simulation and theory analysis, but seldom researches used the swept blade technology in the steam turbine stage. So, this paper changed the swept height and the swept angle to form three blades (fore-sweep, aft-sweep, and prototype blade) and studied the influence of axial sweep on the aerodynamic performance of steam turbine HP stage with NUMECA software. The numerical simulation results indicated that the axial aft-swept can improve the aerodynamic performance of HP steam turbine cascades than the prototype blade.

\section{Geometric Model and Definition of Axial Sweep}

By using super-critical HP steam stage blade as prototype blade $(\mathrm{PB})$ and changing the sweep angle $(\mathrm{A})$ and sweep height $(\mathrm{H})$, we can obtain two new blades, including axial fore-swept blade (SWF) and axial aft-swept blade (SWB), through changing the stacking line.

According to the tilt direction of the coming flow compared with the leading edge (LE) line of the blade, swept blades include SWF and SWB. SWF means that the LE line tilts against the direction of coming flow, and, on the contrary, it is SWB. The geometric definition of the axial sweep was shown in Figure 1. TE is the trailing edge. SWF and SWB denoted the axial sweep angles are $+20^{\circ}$ and $-20^{\circ}$, respectively, and the sweep heights are all 30 percent of the blade height. 


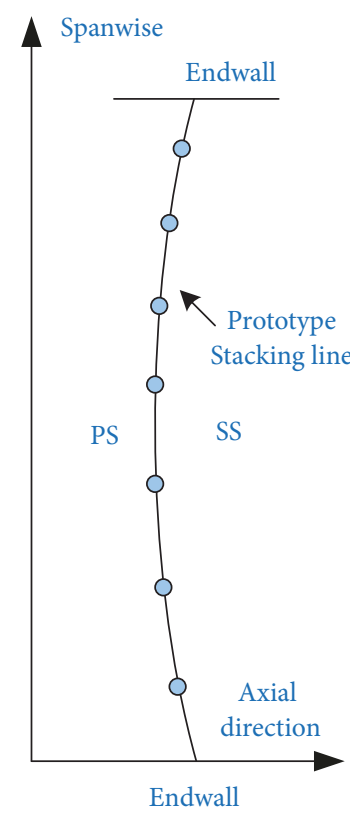

(a)

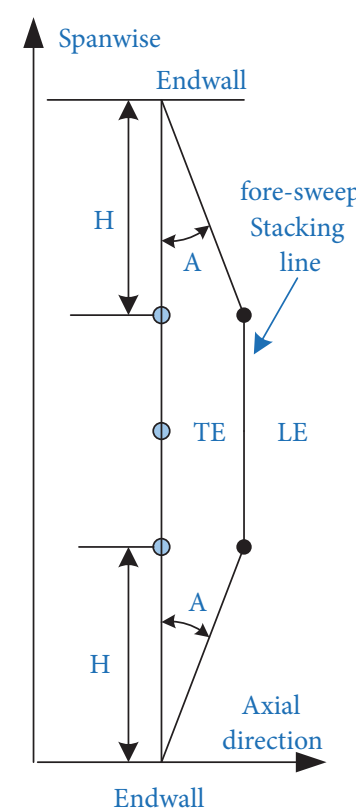

(b)

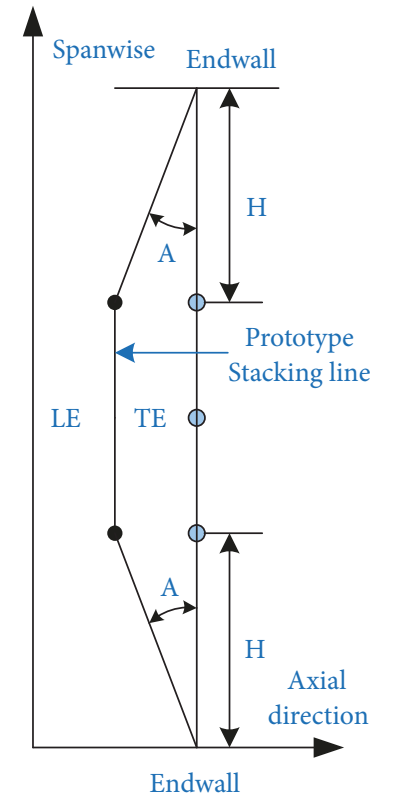

(c)

FIgURe 1: Prototype blade, fore-swept, and aft-swept blade: (a) prototype blade; (b) fore-swept blade; (c) aft-swept blade.

TABLE 1: Geometric parameter of prototype blade.

\begin{tabular}{lcc}
\hline Geometric parameter & Static blade & Rotor blade \\
\hline Tip Diameter $(\mathrm{mm})$ & 1249.39 & 1099.2 \\
Blade Height $(\mathrm{mm})$ & 157.29 & 166 \\
Diameter to Height Ratio & 6.94 & 6.62 \\
Chord length $(\mathrm{mm})$ & 64.37 & 71.86 \\
Aspect Ratio & 2.44 & 2.31 \\
Pitch-Chord Ratio & 0.778 & 0.801 \\
Blade Number & 64 & 60 \\
Blade Inlet Angle & $65.5^{\circ}$ & $53.5^{\circ}$ \\
Blade Outlet Angle & $17.5^{\circ}$ & $17.5^{\circ}$ \\
\hline
\end{tabular}

Figure 2 depicts the 3D-model of the static blade and the tip and root of the blade profile. Figure 3 depicts the 3Dmodel of the rotor blade and the tip and root of the blade profile. The geometric detail parameters of static and rotor blades are shown as Table 1.

\section{Computing Method}

3.1. Grid Mesh and Boundary Conditions. The simulation boundary condition was same as the real working conditions. The numerical simulation was conducted by NUMECA software. As shown in Figures 4 and 5, the total computing grids were 1,000,000 nodes, adopting $\mathrm{H}-\mathrm{O}-\mathrm{O}-\mathrm{H}$ combination type. The inlet part of static blade cascades was H-type; the flow passage parts of static and rotor blade cascade were all O-type; the outlet part of rotor blade cascades was H-type. The rotor and the stator were linked with mixing plane. Inlet total pressure was $5.95 \mathrm{MPa}$; total inlet temperature was $625 \mathrm{~K}$; static outlet pressure was $5.02 \mathrm{MPa}$. The rotational speed of the rotor was $3000 \mathrm{r} / \mathrm{min}$. The simulation computation turbulence model was $k-\varepsilon$ model. Inlet turbulence intensity was $5 \%$. To observe the boundary layer's effects, the mesh structure around the blade was very fine; the value of $y+$ was considered as below 20 .

3.2. Test Method. Figure 6 depicted the test low-speed wind tunnel. The flow medium for wind tunnel was provided by a centrifugal fan driven by a $75 \mathrm{~kW}$ prime motor. The airflow flows through a wind pipe with a certain length and then enters a stabilizing pipe with $1.5 \mathrm{~m}$ diameter. Two sets of stabilizing net and a set of diffuser grid were installed in the stabilizing barrel. The stabilizing also was called damping screen; its function was damaging the bigger vortexes into small vortexes and decreasing the flow turbulence scale.

The diffuser grid also was called flow straightener that can improve the uniformity of airflow. A certain even low turbulence airflow flowed out from the stabilizing pipe into the fan-shaped convergence-device with a big convergence rate. These airflows will be uniformed more than before by accelerating and flowed into the fan-shaped convergencedevice. At last, the airflow flows through the test section and the tail section of the fan-shaped barrel into the air. The test equipment provided a very even initial flow field for the cascade model. The test data was collected by the autotesting system of the wind tunnel.

As shown in Figure 7, five-hole probe is a basic and common instrument to measure the time-averaged characteristic parameters of airflow (including velocity magnitude and direction, total pressure, and static pressure). Because of the simple measure theory of this measure method, convenient using method and uneasy damage and convenient maintenance, the five-hole probe is still one of the key measure methods for time-averaged flow field at present. 


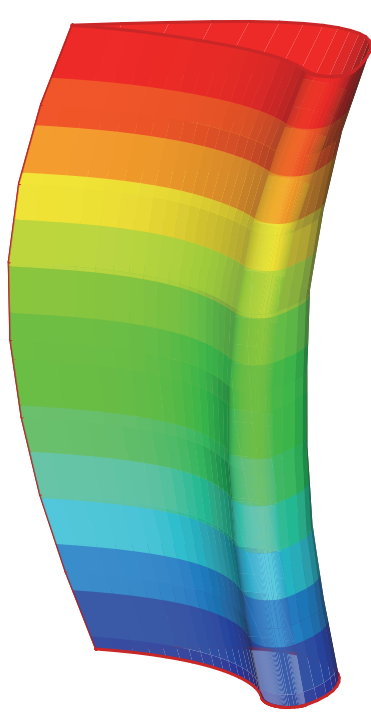

(a)

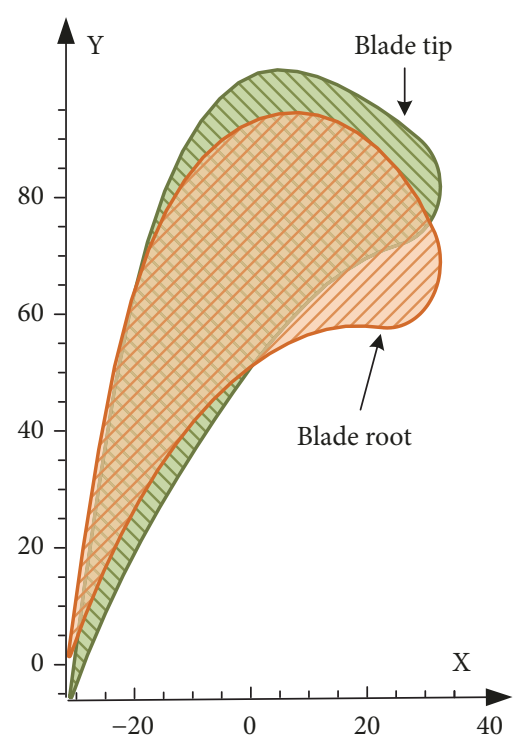

(b)

FIGURE 2: Static blade model: (a) 3D-blade; (b) tip and root of blade profiles.

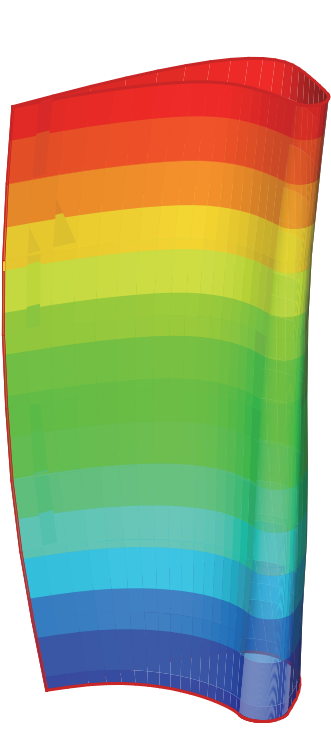

(a)

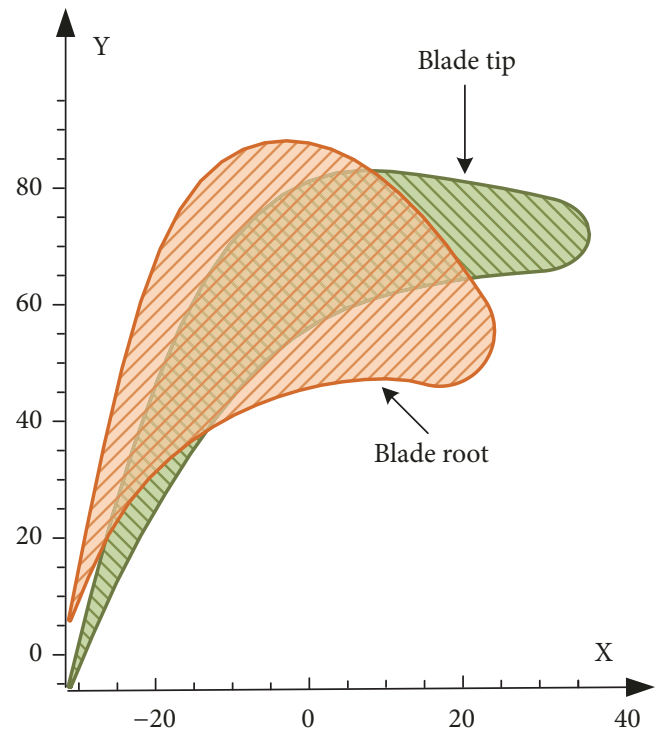

(b)

FIGURE 3: Rotor blade model: (a) 3D-blade; (b) tip and root of blade profiles.

The ink-marks method is a wall flow display method. When using, the ink droplet is dropped at the appropriate position of the blade or the upper and lower end walls. When the fan reaches normal working operation, the airway venting valve is opened to control the flow rate of the airflow that is roughly equivalent to the flow rate during the measurement. Under the action of the high-speed airflow, the ink droplets are flowing along the blade surface and the end wall and are dragging out a certain trajectory. These traces can be considered as the streamline of the object surface. In this experiment, the ink surface method was used to display the blade surface of the experimental cascade and its upper and lower end walls.

The low-speed wind tunnel self-test system was used in the experiment. The positioning angle error of the fivehole probe was less than 1, and the positioning error of the measuring point was $0.5 \mathrm{~mm}$. During the experiment, due to take the method of several points average, the pressure fluctuation during measurement was not large, and the error mainly came from the error of the calibration coefficient. The calculations showed that the error of the measurement results did not exceed 0.03 , but the total pressure and airflow angle 


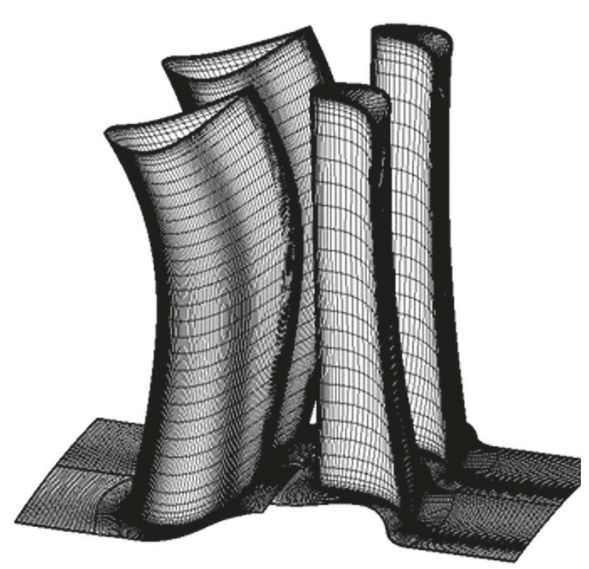

(a)

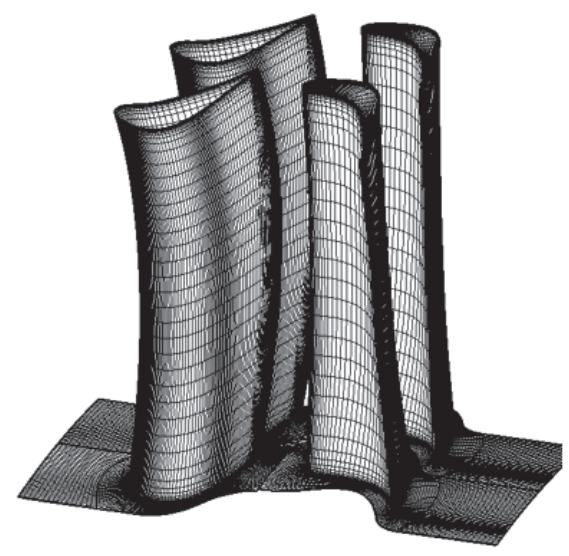

(b)

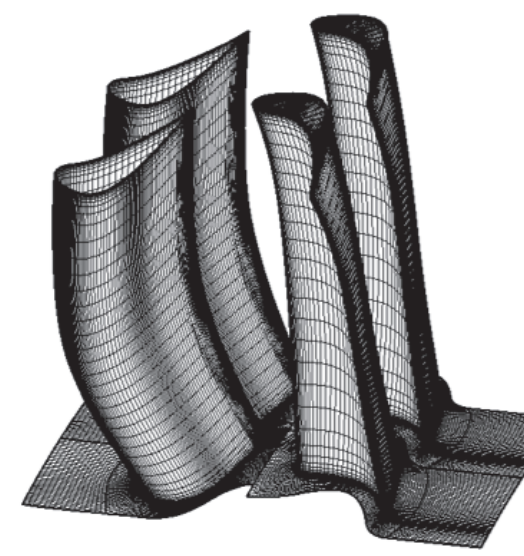

(c)

FIGURE 4: 3D mesh of three stages: (a) SWF stage grid mesh; (b) PB stage grid mesh; (c) SWB stage grid mesh.

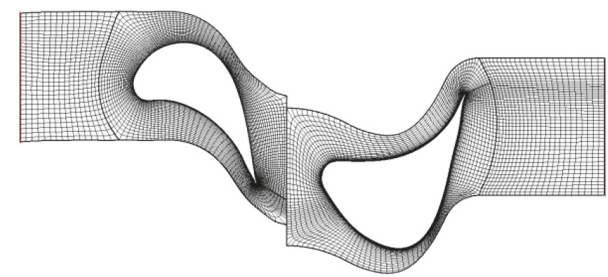

(a)

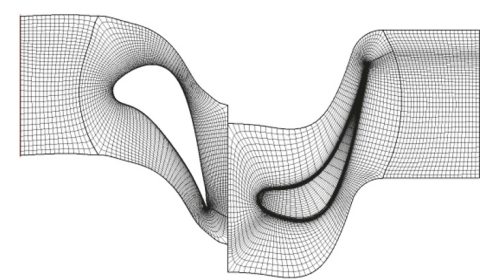

(b)

Figure 5: 2D mesh of root and tip: (a) blade root grid mesh; (b) blade tip grid mesh.

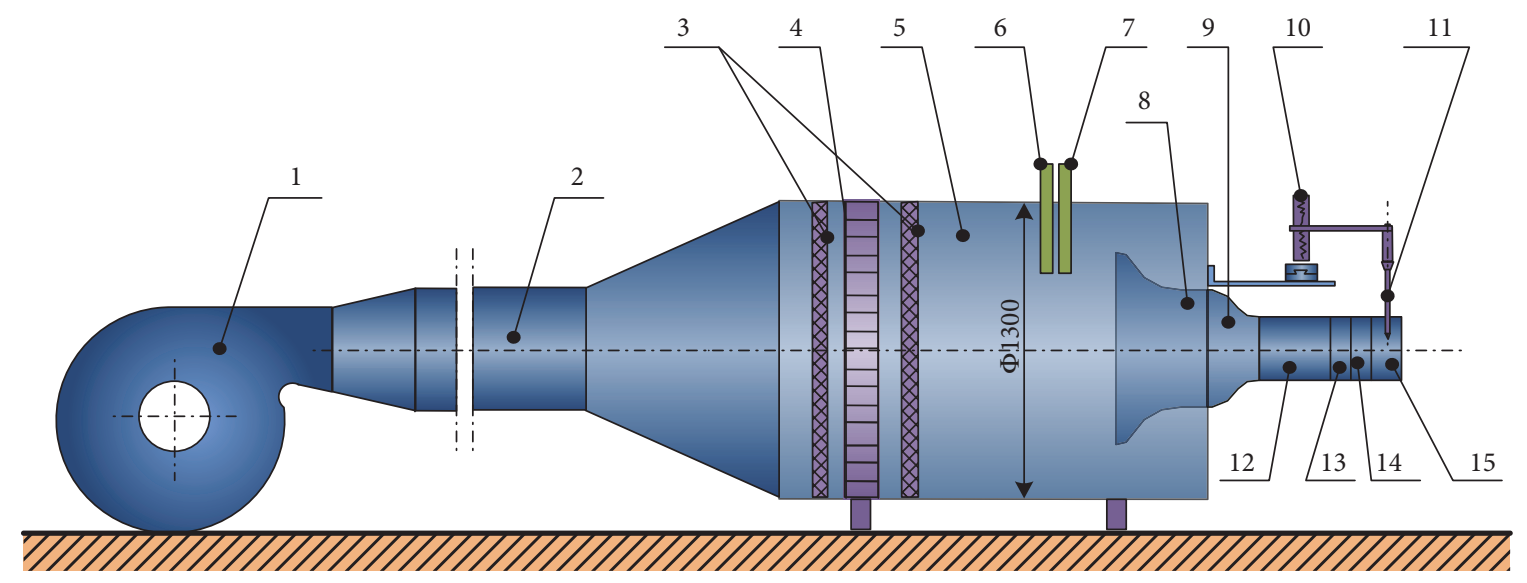

FIGURE 6: Schematic of wind tunnel and cascade: 1-fan; 2-duct; 3-rectification net; 4-rectifier grid; 5-cylinder; 6-total pressure probe; 7temperature sensor; 8-convergence section I; 9-convergence section II; 10-fan measurement coordinate; 11-five-holes probe; 12-straight sector tube; 13 -experimental cascade; 14 -experimental blade; 15 -side plates.

errors were high in the high loss zone. The error of the probe positioning angle mainly affected the secondary flow velocity; that is, the secondary flow vector was most sensitive to the error of the corner angle.

3.3. Simulation Results vs. Tested Results. Testing results and simulation results of static cascades tip-endwalls and rotor cascades root-endwalls were contrasted in the Figures 8 and
9. The numerical simulation of the leading edge saddle point location, the rolling-line of a branch of the suction side of horseshoe vortex location entering the blade suction, and the rolling-line of a branch of the pressure side of horseshoe vortex location entering the adjacent blade suction surface had a very good meeting with the testing results.

Figures 10 and 11 indicated the comparison of experimental and calculated results of the streamline in suction surface 


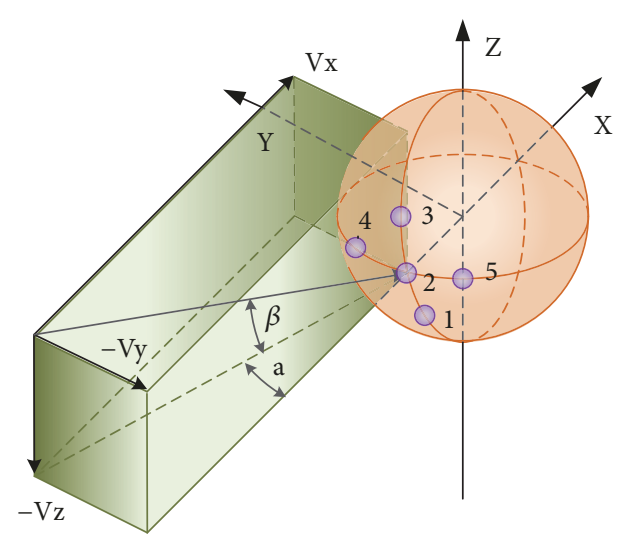

FIGURE 7: Five-hole spherical probe geometry and its coordinates.

of static blade and rotor blade; the calculated results were consistent with the experimental results, respectively.

Figures 12 and 13 depicted the static pressure coefficient curves contrasts between the testing results and the simulating results of the middle span profile surfaces of the prototype static blade and the prototype rotor blade, respectively. Seen from Figures 8 to 13, the testing value and the simulating value of static pressure had a good meeting at all the blade profiles. The difference between testing value and simulating value was in the scope of computing error that proved the computing results of static pressure coefficient were believable.

\section{Aerodynamic Performance of HP Stage}

4.1. Distribution of Pitch-Wise Averaged Cps. The static pressure gradient was decided by three factors: (1) when airflow was flowing in the curving passage; the peripheral speed was flowing along the blade span. Because of the centrifugal inertia force induced by the peripheral speed, a positive radial pressure gradient along the blade span was formed; (2) the radial component force of blade force was distributed along the blade span. This radial component force was relation with the radial stacking line. Balanced with the radial component force of the blade force, a radial static gradient was produced; (3) a radial vortex gradient was induced by a concentrated vortex in the flow channel. Generally, the vicinity of the center of the concentrated vortex was the lowest pressure point along the blade span, and the negative pressure gradient from the end wall to the lowest pressure point was a positive pressure gradient from the lowest pressure point to the middle of the blade. The static pressure gradient along the blade span was the vector sum of above three pressure gradients.

Because the PB profile was rear-loaded profile, its negative pressure gradient area was very little and appeared after the 0.6 relative axial location. Rear-loaded blade would greatly weaken the secondary flow in both endwalls. The curved angle and swept angle of PB cascades were very little, so the incoming flow was a uniform distribution, and the Cps were changed very little along spanwise. As shown in Figure 14, the geometry of leading edge of SWB stage had an impact on the inlet flow field, and the steam flow in middle spanwise firstly

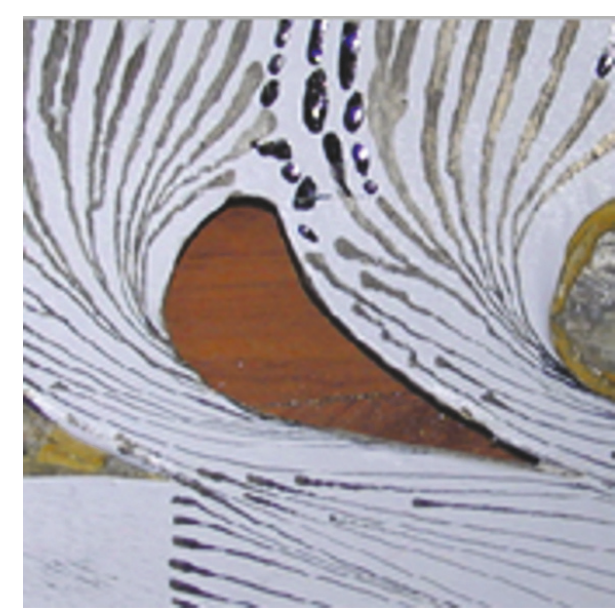

(a)

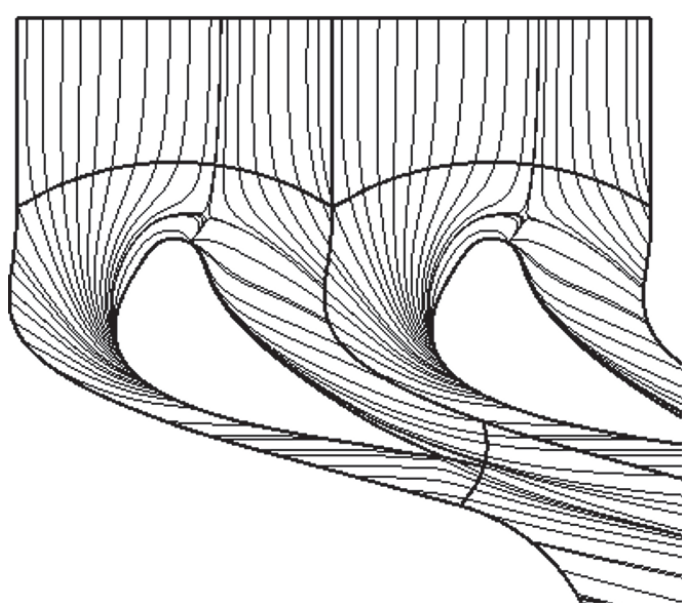

(b)

FIGURE 8: Streamline of the static blade shroud: (a) test streamline; (b) computed streamline.

entered the passage, and in both endwalls later, therefore the pressures in both indwells were bigger than in the middle part. In a word, the "C" type pressure distribution was formed by SWB stage. As for SWF stage, steam flow firstly entered both endwalls and in middle spanwise later, so the negative "C" pressure distribution was formed in the SWF cascades passage.

The lowest pressure point of SWB stage was at nearly the same location as the PB stage, and its negative pressure gradient section was little. The negative pressure gradient was strengthened from the endwalls to the core of passage vortex and pushed the low energy flow of boundary layer in the endwalls into the main flow, so the endwalls boundary layer became thick slower than the PB stage and delayed the separation of the boundary layer. In a word, the SWB stage improved the flow properties in the endwalls and made the pressure loss less than the PB stage. The SWF formed negative "C" pressure distribution, so the passage vortex was lifted to the middle blade and shorter than the PB stage. The strength and coverage of passage vortex were also weakened, so the 


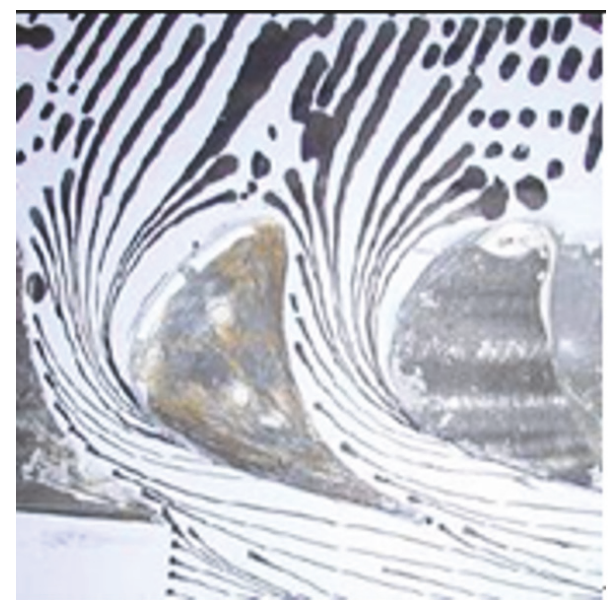

(a)

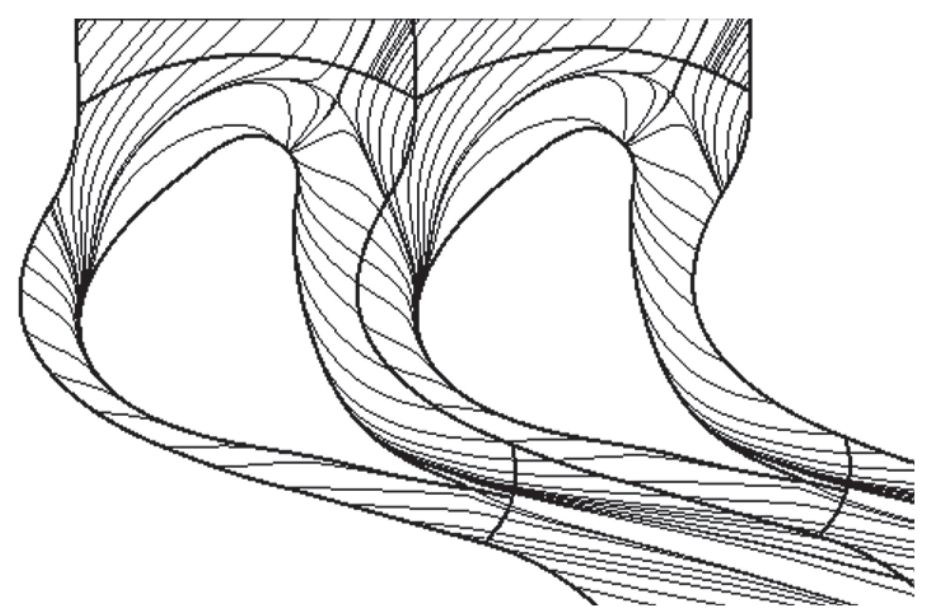

(b)

FIGURE 9: Streamline of rotor blade hub: (a) test streamline; (b) computed streamline.

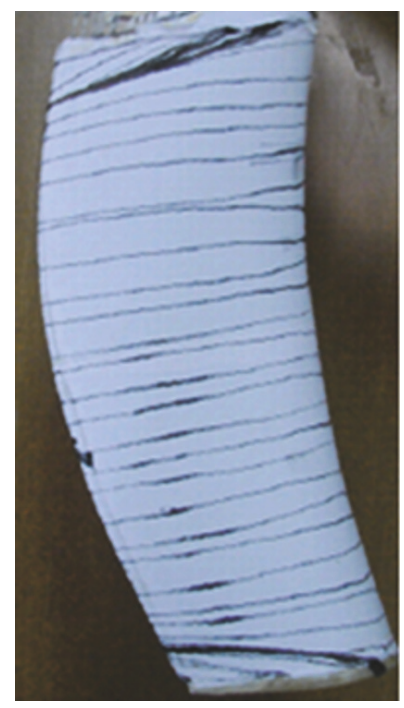

(a)

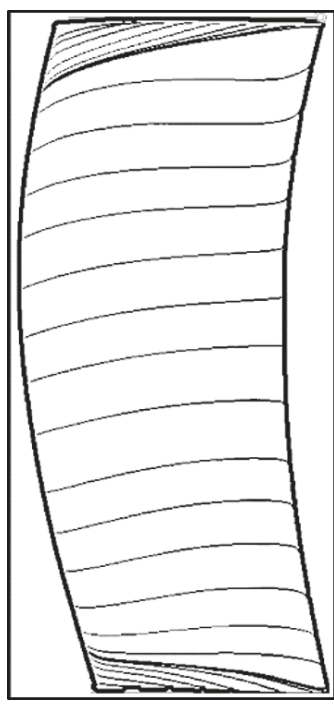

(b)

Figure 10: Streamline of static blade suction surface: (a) test result; (b) computed result.

lower energy flow in the endwalls was not absorbed effectively and increased the flow loss in the endwalls.

4.2. Distribution of Loss Energy Loss Coefficient along Spanwise. The loss energy loss coefficient was defined as (1):

$$
\xi=\frac{\left(P_{s} / P^{*}\right)^{0.2587}-\left(P_{s} / P_{0}^{*}\right)^{0.2587}}{1-\left(P_{s} / P_{0}^{*}\right)^{0.2587}}
$$

$\xi$ is loss energy loss coefficient;

$P_{s}$ is static pressure;

$P^{*}$ is gauging point total pressure;

$P_{0}^{*}$ is total pressure before cascades.

The distribution of the energy loss coefficient along the blade span showed that the loss at both ends and the middle of the cascade increased with the development of the flow and the development and thickening of the wall boundary layer.

The pressures in both endwalls of SWF were smaller than at middle part, so there was positive pressure gradient from the middle part to both endwalls along spanwise, and a strong "C" type energy loss distribution was formed in the surface of SWF. SWF would result in that low energy boundary layer flowed into the up and root of the cascades, and the loss area was bigger than before. We can see from Figure 15 that the down passage vortex loss and the endwalls boundary layer losses were connected; the tip passage vortex loss and the leakage vortex loss were also connected to form an area that was also connected with the boundary layer loss of indwells. The flow loss distribution of SWB stage in the scope of the blade height was the same as the PB stage, but the part loss was less than the PB stage. Referring to the Cps distribution 


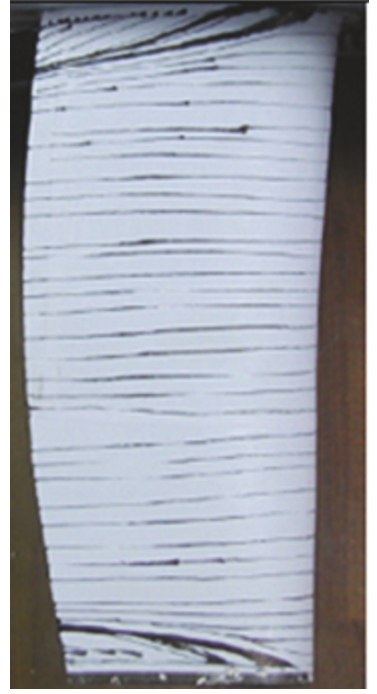

(a)

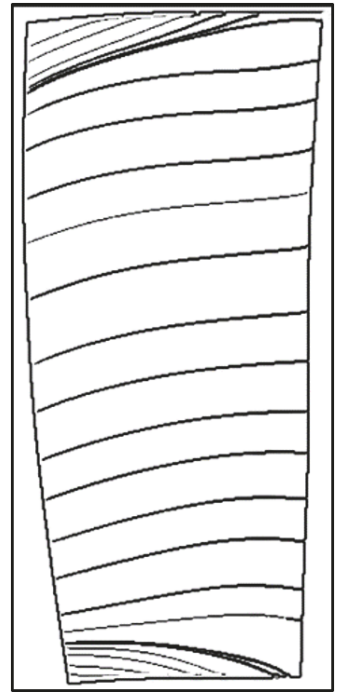

(b)

FIGURE 11: Streamline of rotor blade suction surface: (a) test result; (b) computed result.

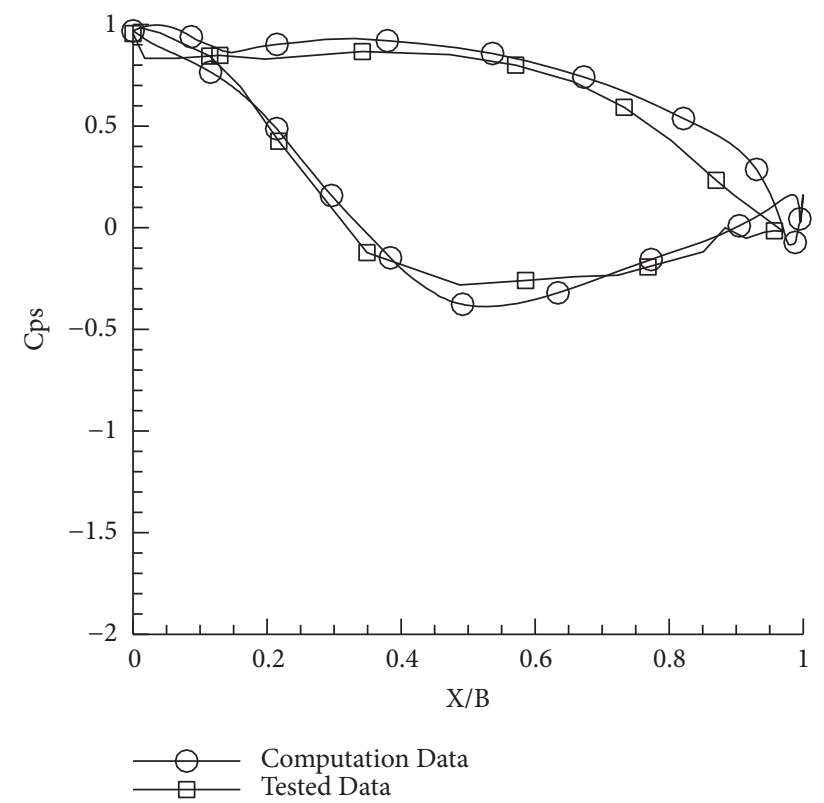

FIGURE 12: Static pressure coefficient distribution along static blade profile.

of Figure 15, the SWB could form a "C" type of pressure distribution as the positive curved blade. The " $\mathrm{C}$ " type of pressure distribution could absorb the low energy boundary layer flow in the endwalls and decrease the secondary flow loss. In other words, the "C" type of pressure distribution could improve the performance of passage flow.

4.3. Flow Angle. The distribution of the average airflow angle along the blade span was one of the important parameters of the aerodynamic performance of the cascade. The distribution of the parameter along the blade span reflected the

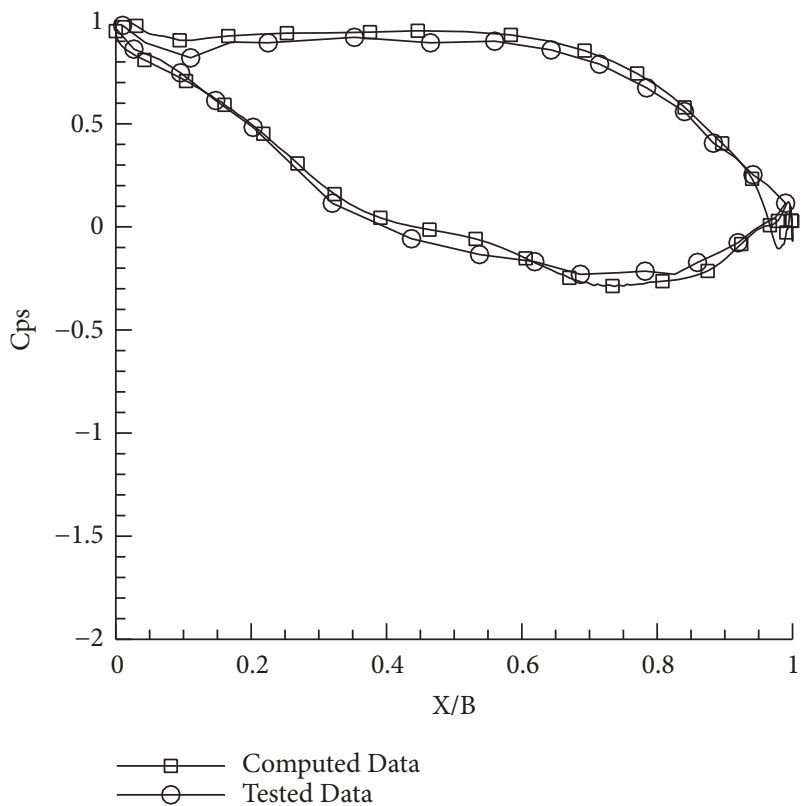

FIGURE 13: Static pressure coefficient distribution along rotor blade profile.

development of the boundary layer of the blade surface and affected the turning degree of airflow and the aerodynamic load along the blade span. The distribution along the blade span, in the redesign process, also affected the incidence angle of the subsequent cascade. In the cascade with gaps, due to the existence of the tip clearance, a part of the airflow will directly enter the adjacent flow channel across the tip of the blade, which will greatly reduce the airflow angle near the tip of the blade.

The pitch-wise averaged flow angle curves along spanwise at the outlet of static blade cascades were shown in Figure 16. 


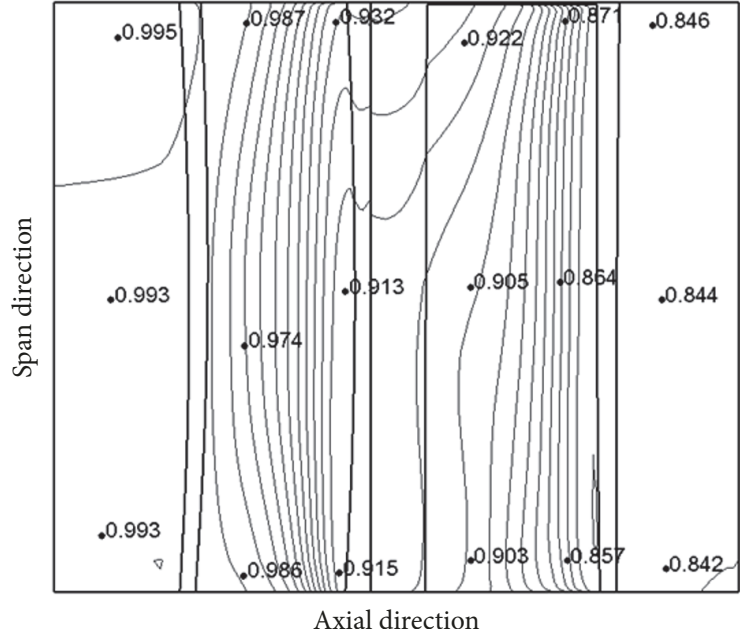

(a) PB stage

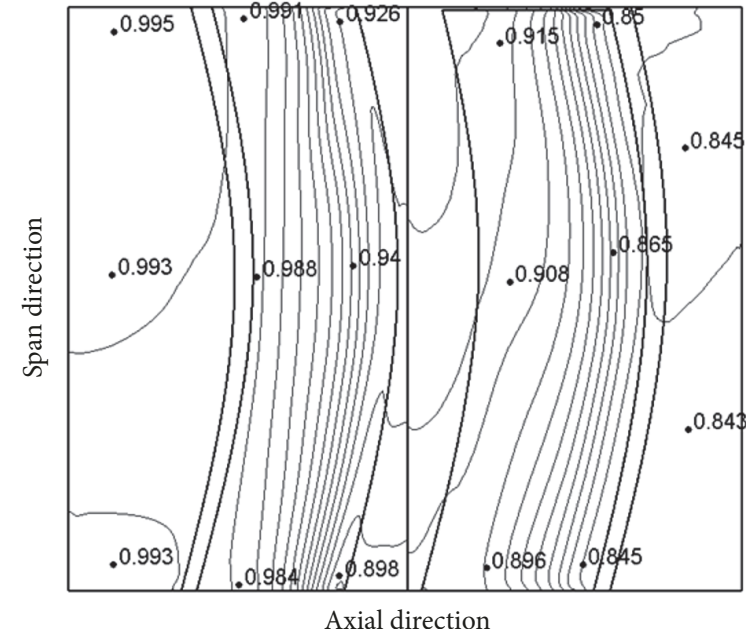

(b) SWF stage

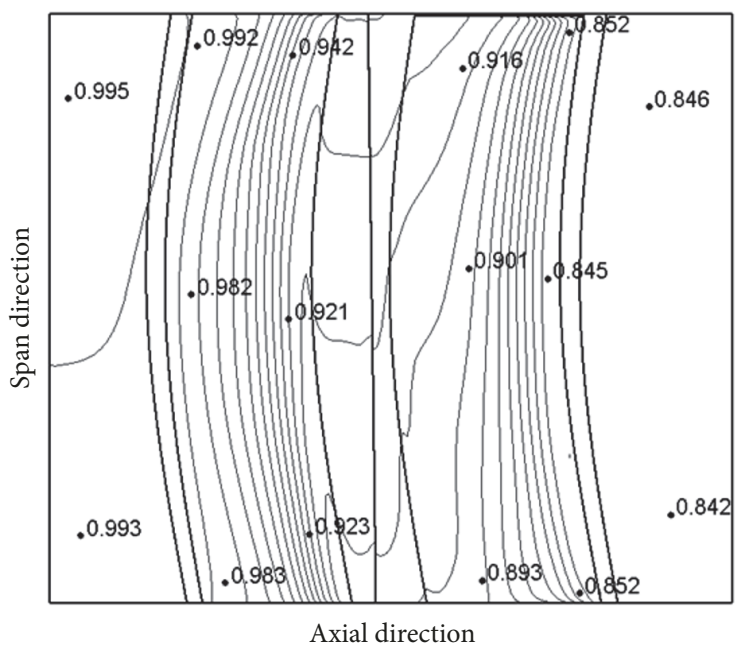

(c) SWB stage

FIGURE 14: Distribution of pitch-wise averaged Cps: (a) PB stage; (b) SWF stage; (c) SWB stage.

Within the scope of $0 \sim 20 \%$ and $80 \% 100 \%$ relative blade height, the flow angle changed more than another scope of blade height. This changing flow angle was due to the lowest pressure point in the suction surface of SWF move to the leading edge, and the pressure expanding section increased in the scope of the oblique section of the stacking line of SWF cascades. The strengthened positive pressure gradient resulted in the fact that blade load was reduced, and the boundary layer was thickened near the endwalls. Because of the gas leakage of the blade top, the flow angle deflected greater than another type blade, and the flow angle uniformity along spanwise of SWF had a bad impact on the incidence of the rear stage. The uniformity of the averaged flow angle of SWB along spanwise was better than SWF and $\mathrm{PB}$. As regards the SWF stage, the lowest pressure points on the suction surface of the SWB stage moved to the trailing edge. The expanded pressure section of pressure surface decreased, so the low energy boundary layer was becoming thin, and outlet flow angle of SWB stage deflected smaller than SWF stage.

4.4. Degree of Reaction. When the steam passed through the turbine stage, the thermal energy was first converted into kinetic energy in the nozzle cascade, and then the kinetic energy was converted into mechanical energy in the rotor cascade so that the impeller and the shaft were rotating. Thereby, the steam turbine completed the work task by using steam heat energy. After expanded in the nozzle, the expanded steam entered the rotor blade flow path. If the steam flow did not continue to expand and accelerate in the rotor blade passage but only changes its flow direction with the shape of the steam passage, the centrifugal force acted on the rotor blade passage was called impulse force. The mechanical work done by the steam at this time was equal to the change amount of kinetic energy in the cascade. The steam continued to expand and accelerate with the changing 


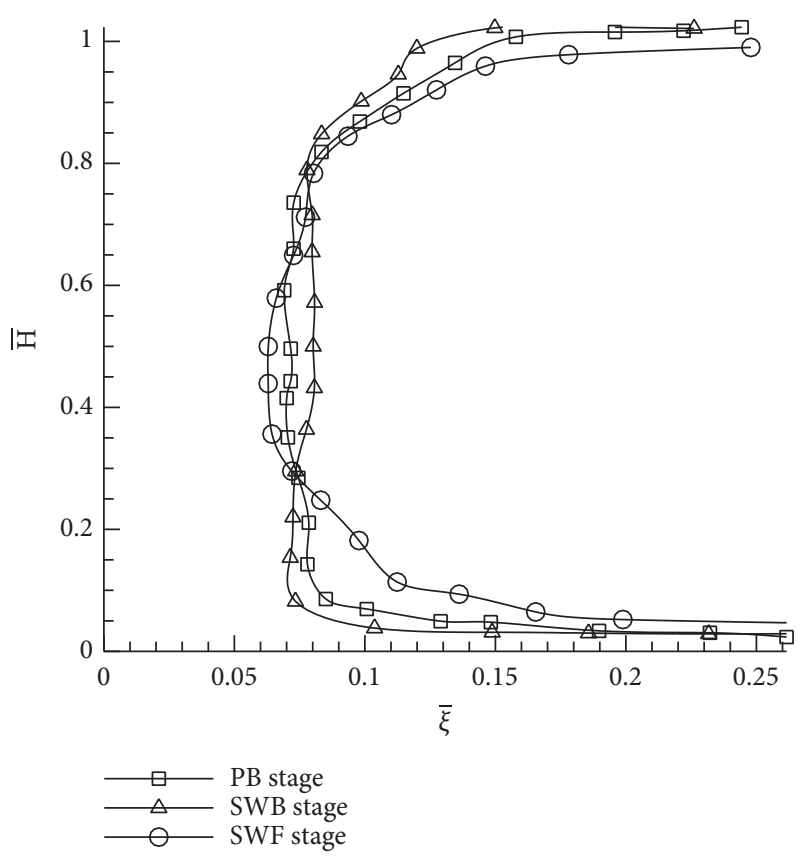

FIGURE 15: Distribution of $\xi$ along spanwise.

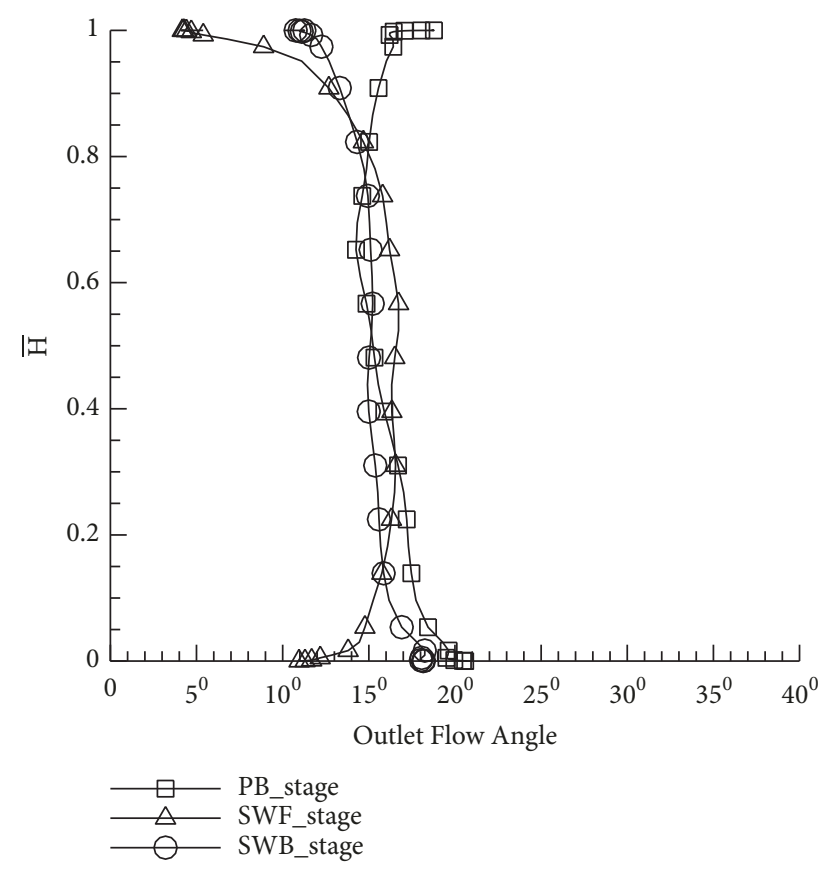

FIGURE 16: Distribution of pitch-wise averaged flow angle along spanwise.

of the flow direction in the rotor blade passage; that is, not only does the steam flow change the direction, but also its specific enthalpy decreased and expanded, and its velocity also increased greatly. When the accelerated steam flowed out of the passage, a reaction force opposite to the outflow direction of the steam flow was applied to the rotor blade cascade, which was called reaction force. The introduction of the degree of reaction was to measure the expansion

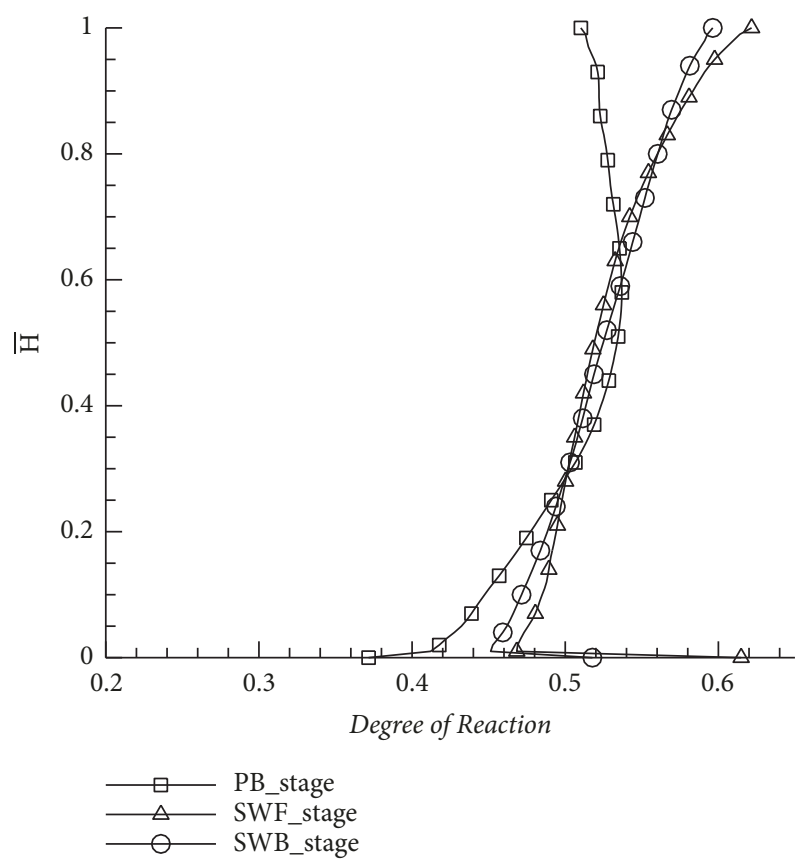

FIGURE 17: Distribution of degree of reaction along spanwise.

degree of the steam in the cascade and the magnitude of the impulse force and the reaction force in the stage. The degree of reaction was equal to the ratio between the ideal specific enthalpy drop of rotor and the stagnation ideal specific enthalpy of stage.

Figure 17 showed that, along with a spanwise direction, the degree of reaction (DR) increased gradually, and it was consistent with the characteristics of the reaction turbine. Within the scope of $20 \%$ relative height in the blade root, the DRs of the SWF stage and SWB stage were larger than the PB stage. The increase of DR could increase the positive pressure gradient from the inlet to the outlet and enhance the flow speed in the scope of blade root that made the flow smoothly. But the DR in blade roots was not the bigger, the better; a larger DR may lead to air leakage. Within the scope of $70 \% \sim 100 \%$ relative height at the blade tip, the DRs of SWF stage and SWB stage were larger than the PB stage too, and the SWF stage was bigger than the SWB stage. The increase of DR was likely to increase the tip clearance leakage losses.

\section{Conclusion}

This paper had researched the influence of swept technology to the high-pressure steam blade cascades by the low wind flow tunnel and CFD simulation. The research results indicated that the swept blade can greatly influence the aerodynamic performance of the eighth high-pressure steam stage cascades. The simulated results had met with the test results. We achieved the following conclusions.

The static pressure gradient was decided by three factors. (1) When airflow was flowing in the curving passage, the peripheral speed was flowing along the blade span. (2) The radial component force of blade force was distributed along 
the blade span. (3) A radial vortex gradient was induced by a concentrated vortex in the flow channel.

As to the axial aft-swept blade, its leading edge's geometry would influence the inlet flow field. The value of passage pressure distribution was higher in both endwalls part of the blade than the middle part and formed stronger "C" type distribution than PB stage.

The SWF stage changed the pressure distribution and was not like the PB stage. The pressure distribution of SWF was lower in both endwalls of the blade than the middle part of the blade; in other words, it was a negative " $C$ " type pressure distribution. The " $C$ " type pressure distribution became stronger more and more in the passage flow direction of SWB stage. The negative " $C$ " type pressure distribution of SWF stage also reflected the same distribution rule.

The total pressure loss and the pitch-averaged flow angle distribution along spanwise indicated that, as regards the $\mathrm{PB}$, the axial-swept blade could change the flow loss distribution at the same working condition. From a comparison of the energy loss distribution curve along the spanwise, the flow loss of SWB was the least; the PB was the middle; the SWF was the biggest. The SWB stage improved the passage flow and reduced the flow loss.

\section{Appendix}

\section{A. Navier-Stokes Equations}

In this simulation work, the flow medium was single-phase, isothermal, and compressible flow of gas inside the steam turbine passage.

The internal flow of steam turbine follows the rules of mass conservation equation, momentum conservation equation, and energy conservation equation [30]. [31]:

Mass conservation equation for flow model is as follows

$$
\frac{\partial \rho}{\partial t}+\frac{\partial(\rho u)}{\partial x}+\frac{\partial(\rho v)}{\partial y}+\frac{\partial(\rho w)}{\partial z}=0
$$

where

$\rho$ is density, $\mathrm{kg} / \mathrm{m}^{3}$;

$T$ is time, s;

$u, v$, and $w$ are velocity vector components in the $x, y$, and $z$ directions, respectively.

Momentum conversation equation for the internal flow model of the steam turbine is as follows.

Regarding the rule, the momentum conversation equation in the $\mathrm{x}, \mathrm{y}$, and $\mathrm{z}$ directions can be expressed as follows:

$$
\begin{aligned}
& \frac{\partial(\rho u)}{\partial t}+\operatorname{div}(\rho \vec{u}) \\
& =-\frac{\partial p}{\partial x}+\frac{\partial \tau_{x x}}{\partial x}+\frac{\partial \tau_{y x}}{\partial y}+\frac{\partial \tau_{z x}}{\partial z}+F_{x} \\
& \frac{\partial(\rho v)}{\partial t}+\operatorname{div}(\rho \overrightarrow{v u}) \\
& =-\frac{\partial p}{\partial y}+\frac{\partial \tau_{x y}}{\partial x}+\frac{\partial \tau_{y y}}{\partial y}+\frac{\partial \tau_{z y}}{\partial z}+F_{y}
\end{aligned}
$$

$$
\begin{aligned}
& \frac{\partial(\rho w)}{\partial t}+\operatorname{div}(\rho w \vec{u}) \\
& =-\frac{\partial p}{\partial z}+\frac{\partial \tau_{x z}}{\partial x}+\frac{\partial \tau_{y z}}{\partial y}+\frac{\partial \tau_{z z}}{\partial z}+F_{z}
\end{aligned}
$$

where

$p$ is pressure on the elemental flow volume;

$\tau_{x x}, \tau_{y x}, \tau_{z x}$ are vector components of viscous stress;

$F_{x}, F_{y}, F_{z}$ are body force on the elemental volume.

\section{B. Standard $k-\varepsilon$ Model}

In 1972, using the single equation model, Launder and Spalding [32] proposed a two-equation model and then introduced another equation about turbulent dissipation rate and thus formed $k-\varepsilon$ model.

In the $k-\varepsilon$ model, turbulent dissipation rate was defined as (B.1):

$$
\begin{aligned}
\varepsilon & =\frac{\mu}{\rho} \overline{\left(\frac{\partial u_{i}^{\prime}}{\partial x_{k}}\right)\left(\frac{\partial u_{j}^{\prime}}{\partial x_{k}}\right)} \\
\mu_{t} & =\rho C_{\mu} \frac{k^{2}}{\varepsilon}
\end{aligned}
$$

In the standard $k-\varepsilon$ model, turbulent kinetic energy $k$ and turbulent dissipation rate $\varepsilon$ are two basic unknown quantities; the corresponding transport equations were shown as (B.3) and (B.4):

$$
\begin{aligned}
& \frac{\partial}{\partial t}(\rho k)+\frac{\partial}{\partial x_{i}}\left(\rho k u_{i}\right) \\
& =\frac{\partial}{\partial x_{j}}\left[\left(\mu+\frac{\mu_{t}}{\sigma_{k}}\right) \frac{\partial k}{\partial x_{j}}\right]+G_{k}+G_{b}-\rho \varepsilon-Y_{M} \\
& \quad+S_{k} \\
& \frac{\partial}{\partial t}(\rho \varepsilon)+\frac{\partial}{\partial x_{i}}\left(\rho \varepsilon u_{i}\right) \\
& =\frac{\partial}{\partial x_{j}}\left[\left(\mu+\frac{\mu_{t}}{\sigma_{\varepsilon}}\right) \frac{\partial \varepsilon}{\partial x_{j}}\right]+C_{1 \varepsilon} \frac{\varepsilon}{k}\left(G_{k}+C_{3 \varepsilon} G_{b}\right) \\
& \quad-C_{2 \varepsilon} \rho \frac{\varepsilon^{2}}{k}+S_{\varepsilon}
\end{aligned}
$$

The symbols were depicted as follows:

$G_{k}$ is turbulent kinetic energy due to the laminar flow velocity gradient;

$G_{b}$ is because of the buoyancy induced turbulence energy $k$, for an incompressible fluid, $G_{b}=0$;

$Y_{M}$ denotes pulsation expansion value in the compressible turbulence, for an incompressible fluid, $Y_{M}=0$;

$C_{1 \varepsilon}, C_{2 \varepsilon}, C_{3 \varepsilon}$, and $C_{\mu}$ are empirical constants, according to the Launder recommended values and experimental verification in the future, $C_{1 \varepsilon}=1.44, C_{2 \varepsilon}=1.29, C_{\mu}=$ 
0.09 , and $C_{3 \varepsilon}=0$ or $1 . C_{3 \varepsilon}$ is a buoyancy coefficient for the CFD calculation when the compressible fluid flows. When the mainstream direction is parallel to the direction of gravity, $C_{3 \varepsilon}=1$. When the flow direction is perpendicular to the direction of gravity, $C_{3 \varepsilon}=0$.

$\sigma_{k}$ and $\sigma_{\varepsilon}$ are corresponding to the Prandtl number of turbulent kinetic energy $k$ and dissipation rate $\varepsilon$, respectively, according to the Launder recommended values and the experimental verification, $\sigma_{k}=1.0$ and $\sigma_{\varepsilon}=1.3$.

\section{Nomenclature}

$\begin{array}{ll}\text { A: } & \text { Sweep angle } \\ \text { H: } & \text { Sweep height } \\ \text { HP: } & \text { High pressure } \\ \text { Cps: } & \text { Static pressure coefficient=static } \\ & \text { pressure/incoming total pressure before } \\ & \text { cascade } \\ \text { PB: } & \text { Prototype blade } \\ \text { SWF: } & \text { Axial fore-sweep blade } \\ \text { SWB: } & \text { Axial aft-sweep blade } \\ \text { DR: } & \text { Degree of reaction } \\ \text { X/B: } & \text { Axial relative chord length coordinate } \\ \text { h: } & \text { Blade height. }\end{array}$

\section{Data Availability}

The data used to support the findings of this study are available from the corresponding author upon request.

\section{Conflicts of Interest}

The authors declare no conflicts of interest.

\section{Authors' Contributions}

Zi-Ming Feng contributed to low-speed wind tunnel test, writing article, and analysis. Chenhao Guo contributed to CFD simulation working and data postprocess. Bingkun Wei contributed to drawing the figure and editing of the paper. Wei Cui revised the abstract and conclusion, analyzed the causes of these phenomena, revised the internal mechanisms, and revised the discussion. Huibin Gu contributed to lowspeed wind tunnel test. Jindong Zhang contributed to translation from Chinese into English.

\section{Acknowledgments}

The project was funded by Natural Science Foundation of China (nos. 51774091; 51607035), China Postdoctoral Science Foundation (nos. 2018T110268; 2018M641804), Natural Science Foundation of Heilongjiang province (no. LH2019E018), Heilongjiang Postdoctoral Research Foundation (LBH-Q18029), and Heilongjiang Youth Innovation Talents of Ordinary Undergraduate Colleges and Universities (UNPYSCT-2018046).

\section{References}

[1] L. A. Beatty, M. Savage, and J. C. Emerry, "Low speed cascade tests of two 45 degree swept compressor blades with constant spanwise loading," NACA Report L53L07, Washington DC, USA, 1954

[2] W. R. Godwin, "Effect of Sweep on Performance of Compressor Blade Sections as Indicted by Swept Blade Rotor, Unswept Blade Rotor and Cascade Tests," NACA Report TN4062, Washington DC, USA, 1957.

[3] L. H. Smith and H. Yeh, "Sweep and dihedral effects in axialflow turbomachinery," Journal of Basic Engineering, vol. 85, no. 3, pp. 401-411, 1963.

[4] R. I. Lewis and J. M. Hill, "Influence of sweep and dihedral in turbomachinery blade rows," Journal of Mechanical Engineering Science, vol. 13, no. 4, pp. 266-285, 1971.

[5] J. P. Gostelow and L. H. Smith, "Aerodynamic design and performance of a swept back rotor SW-1," GE Report AEG-175, New Jersey, USA, 1968.

[6] A. R. Wadia, P. N. Szucs, and D. W. Crall, "Inner workings of aerodynamic sweep," Journal of Turbomachinery, vol. 120, no. 4, pp. 671-682, 1998.

[7] T. Sasaki and F. Breugelmans, "Comparison of sweep and dihedral effects on compressor cascade performance," Journal of Turbomachinery, vol. 120, no. 3, pp. 454-463, 1998.

[8] Z. P. Zou, L. D. Zhao, M. Z. Chen, and L. P. Xu, “Threedimensional blading and its influence on blade aerodynamic loading," Journal of Aerospace Power, vol. 13, no. 3, pp. 235-240, 1998.

[9] H. D. Weingold, R. J. Neubert, R. F. Behlke et al., "Reduction of compressor stator endwall losses through the use of bowed stators," in Proceedings of the ASME 1995 International Gas Turbine and Aeroengine Congress and Exposition, Houston, Texas, USA, June 1995.

[10] A. Corsini and F. Rispoli, "The role of forward sweep in subsonic axial fan rotor aerodynamics at design and off-design operating conditions," in Proceedings of the ASME Turbo Expo 2003, collocated with the 2003 International Joint Power Generation Conference, pp. 543-553, Atlanta, Ga, USA, June 2003.

[11] G. S. McNulty, J. J. Decker, B. F. Beacher et al., "The impact of forward swept rotors on tip-limited low-speed axial compressors," in Proceedings of the ASME Turbo Expo 2003, collocated with the 2003 International Joint Power Generation Conference, pp. 613-624, Atlanta, Ga, USA, 2003.

[12] Z. Feng, W. Han, J. Zhong, and H. Yan, "Influence of swept wing on axial steam turbine static cascade aerodynamic," in Proceedings of the ASME Turbo Expo 2008: Power for Land, Sea, and Air, pp. 1087-1096, Berlin, Germany, June 2008.

[13] Z.-M. Feng, W.-J. Han, J.-J. Zhong, and H.-M. Yan, "Influence of axially-swept blades on the aerodynamic performance of a turbine stationary cascade," Reneng Dongli Gongcheng, vol. 24, no. 1, pp. 19-23, 2009.

[14] B. Roy and A. Prajapati, "Part-span application of sweep and lean at turbine blade tips: a low speed experimental cascade study," in Proceedings of the ASME Turbo Expo 2010: Power for Land, Sea, and Air, pp. 1469-1478, Glasgow, UK, June 2010.

[15] Y.-F. Shi, H. Wu, J. Huang, and J.-G. Yang, "Effect of forward swept blade on rotor stability under inlet circumferential total pressure distortion," Hangkong Dongli Xuebao/Journal of Aerospace Power, vol. 27, no. 3, pp. 657-665, 2012.

[16] Z. Liu, R. Xiao, T. Lü, and S. Li, "Effect of swept blade on hump and cavitation characteristics of axial flow pump," Journal of 
Drainage and Irrigation Machinery Engineering, vol. 30, no. 3, pp. 270-273, 2012.

[17] K. Bamberger and T. Carolus, "Optimization of axial fans with highly swept blades with respect to losses and noise reduction," Noise Control Engineering Journal, vol. 60, no. 6, pp. 716-725, 2012.

[18] S. Larwood, C. van Dam, and D. Schow, "Design studies of swept wind turbine blades," Journal of Renewable Energy, vol. 71, pp. 563-571, 2014.

[19] S. Jeong, B. Choi, and K. Kim, "Rotor blade sweep effect on the performance of a small axial supersonic impulse turbine," International Journal of Aeronautical and Space Sciences, vol. 16, no. 4, pp. 571-580, 2015.

[20] M. A. Neshat, M. Akhlaghi, A. Fathi, and H. Khaledi, "Investigating the effect of blade sweep and lean in one stage of an industrial gas turbine's transonic compressor," Propulsion and Power Research, vol. 4, no. 4, pp. 221-229, 2015.

[21] H. Chang, F. Zhu, D. Jin, and X. Gui, "Effect of blade sweep on inlet flow in axial compressor cascades," Chinese Journal of Aeronautics, vol. 28, no. 1, pp. 103-111, 2015.

[22] H. Paresh and S. Abdus, "Marine energy turbine performance: effect of blade sweep," in Proceedings of the 5th International Conference on Advances in Energy Research, ICAER, pp. 15-17, Mumbai, India, 2015.

[23] Y. G. Ding and X. Zhang, "An optimal design method of swept blades for HAWTs," Journal of Renewable \& Sustainable Energy, vol. 8, no. 4, pp. 463-471, 2016.

[24] M. G. Khalafallah, A. M. Ahmed, and M. K. Emam, "CFD study of some factors affecting performance of HAWT with swept blades," International Journal of Sustainable Energy, vol. 36, no. 5, pp. 489-501, 2017.

[25] C. Pavese, T. Kim, and J. P. Murcia, "Design of a wind turbine swept blade through extensive load analysis," Journal of Renewable Energy, vol. 102, pp. 21-34, 2017.

[26] Z.-M. Feng, J. Tan, X. Liu, and C. Wei, "Swept blade influence on aerodynamic performance of steam turbine nozzle cascades," Sädhanā, vol. 43, no. 4, pp. 1-7, 2018.

[27] M. N. Kaya, F. Kose, D. Ingham, L. Ma, and M. Pourkashanian, "Aerodynamic performance of a horizontal axis wind turbine with forward and backward swept blades," Journal of Wind Engineering \& Industrial Aerodynamics, vol. 176, pp. 166-173, 2018.

[28] M. Z. Tang, D. H. Jin, X. Guo, and X. M. Gui, "Effect of circumferential non-uniformity on the inlet flow fields of a swept blade," Aeroengine, vol. 44, no. 4, pp. 8-15, 2018.

[29] A. M. Boulamatsis, T. K. Barlas, and H. Stapountzis, "Active control of wind turbines through varying blade tip sweep," Journal of Renewable Energy, vol. 131, pp. 25-36, 2019.

[30] Z. M. Feng, R. Sun, W. Cui et al., "Research on effects of incidence to turbine guide cascade aerodynamic performance," Tehnicki Vjesnik-Technical Gazette, vol. 26, no. 3, pp. 736-742, 2019.

[31] H. K. Versteeg and W. Malalasekera, An Introduction to Computational Fluid Dynamics: The Finite Volume Method, Wiley, New York, NY, USA, 1995.

[32] Launder and D. Spalding, Mathematical Models of Turbulence, Academic Press, Waltham, Mass, USA, 1972. 


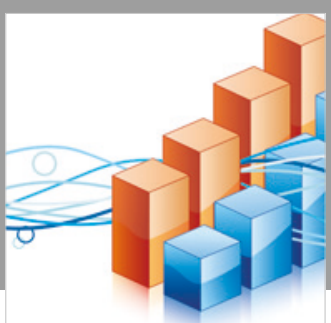

Advances in

Operations Research

\section{-n-m}
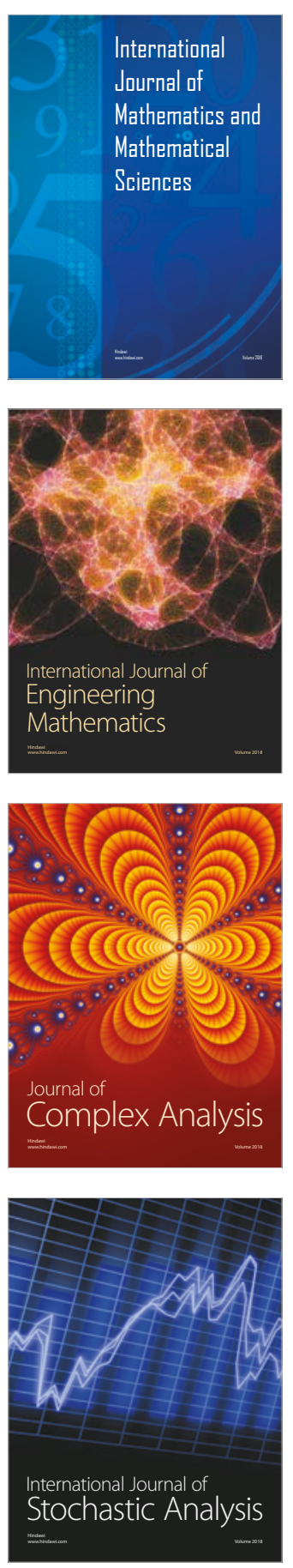
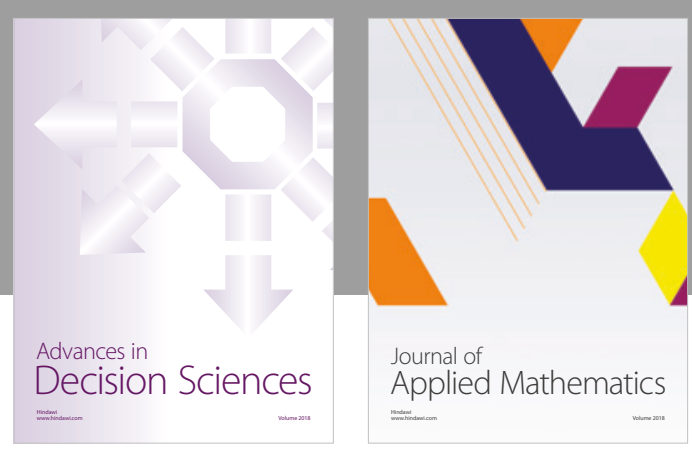

Journal of

Applied Mathematics
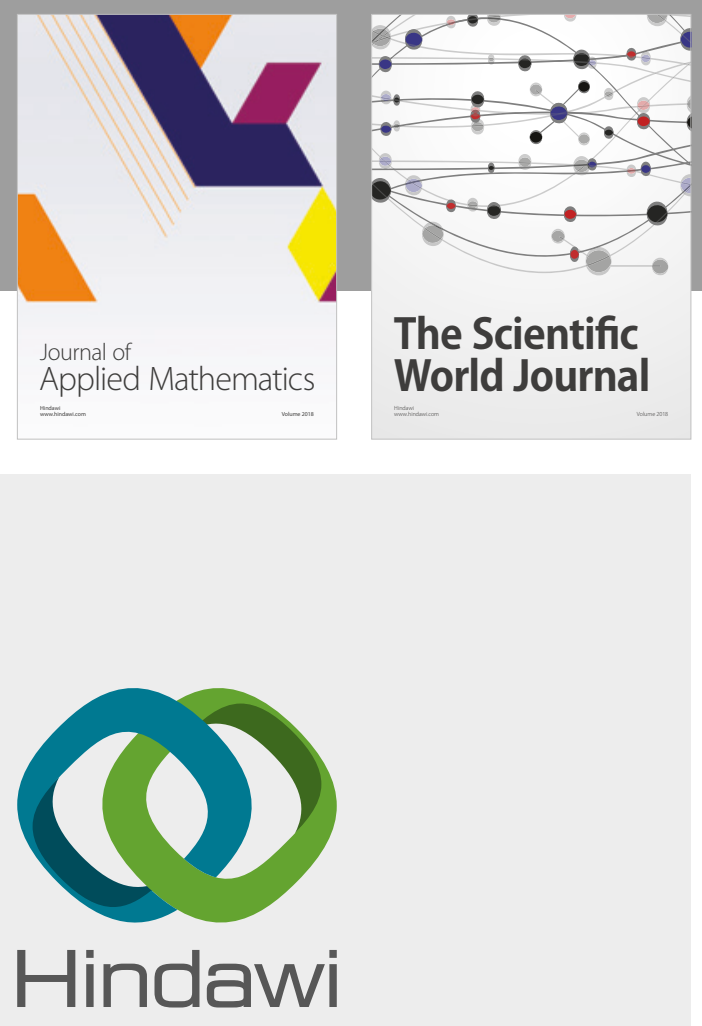

Submit your manuscripts at

www.hindawi.com

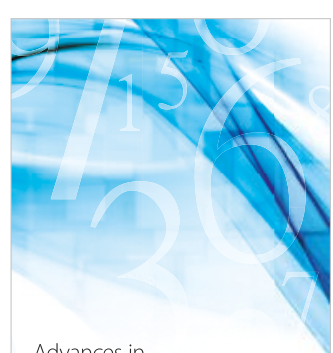

Advances in
Numerical Analysis
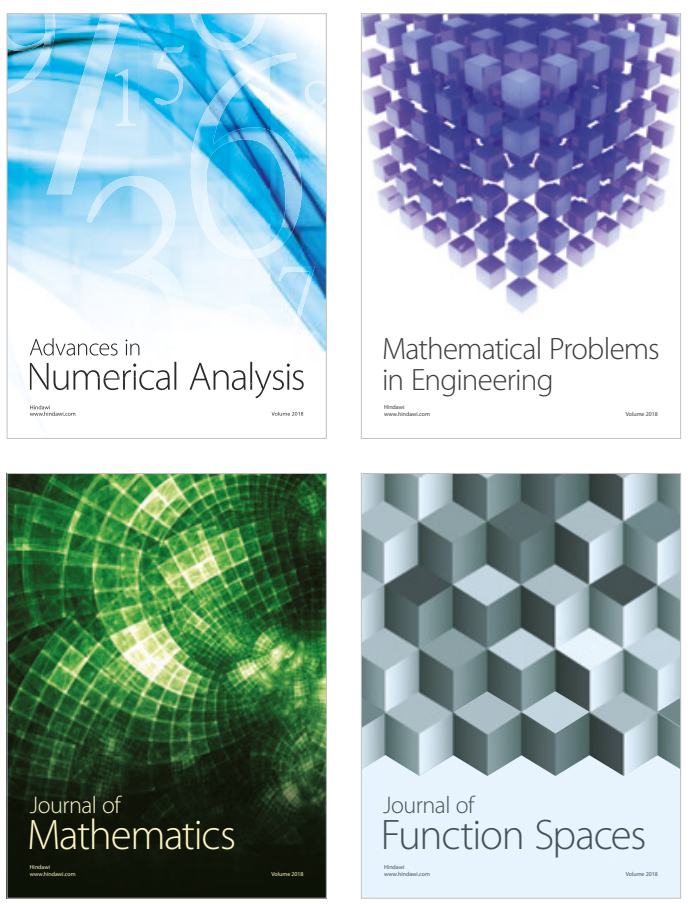

Mathematical Problems in Engineering

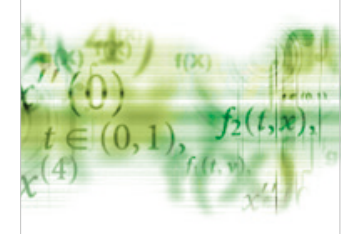

International Journal of

Differential Equations

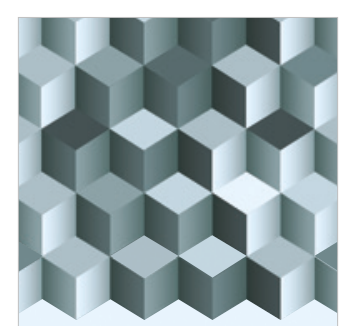

Journal of

Function Spaces

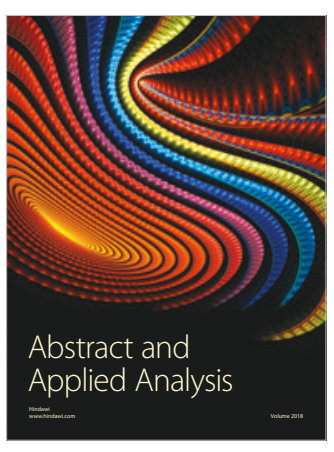

The Scientific

World Journal

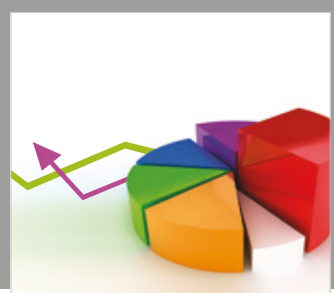

Journal of

Probability and Statistics
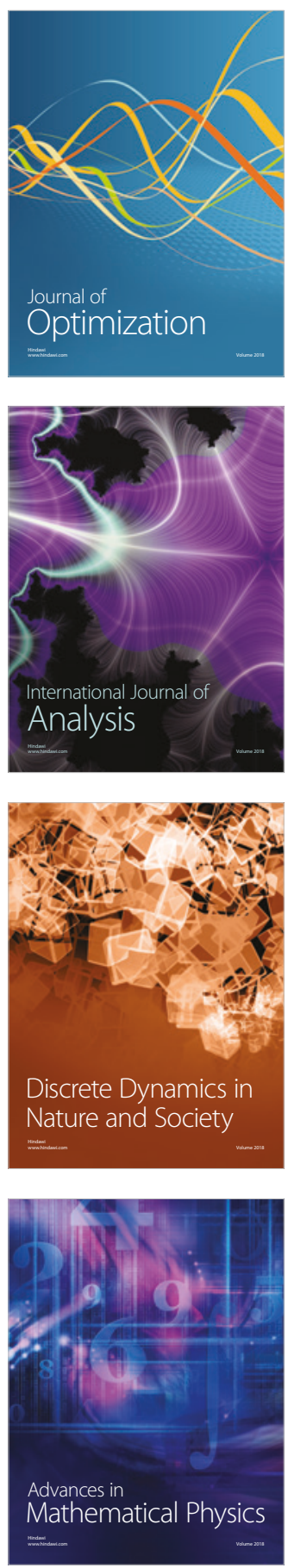